\title{
Bioanalytical Method Development, Validation and Quantification of Metaxalone in Rat Plasma by Liquid Chromatography Tandem Mass Spectrometry
}

Karthikeyan Kandasamy ${ }^{1 *}$, Vasantharaju Surenahalli Gowdra1, Hariprabhu Nammalvar ${ }^{2}$ and ArulKumaran Kottur S Govindarajan²

${ }^{1}$ Department of Pharmaceutical Quality Assurance, Manipal College of Pharmaceutical Sciences, Manipal University, Manipal - 576104, India

${ }^{2}$ Department of Pharmaceutics, KMCH college of Pharmacy, Kalapatti, Coimbatore - 641048, India

\begin{abstract}
A simple, highly sensitive, precise and accurate high-performance liquid chromatographic (LCMSMS) method with mass detection was developed and validated for the rapid quantification of metaxalone (CAS Registry No, 166548-1) in rat plasma samples. The chromatographic separation was achieved with a reverse phase column Agilent XDB $C_{18}(4.6 \times 100 \mathrm{~mm}, 5 \mu)$ and the mobile phase consisted of methanol and $5 \mathrm{~mm}$ ammonium acetate buffer $(80: 20$ $\mathrm{v} / \mathrm{v}$ ) as eluent, at a flow rate of $0.6 \mathrm{~mL} / \mathrm{min}$. Phenytoin (CAS Registry no, 57-41-0) was used as an internal standard. The effluence was ionized by positive electrospray ionization and measured by mass spectrometry. The retention time of metaxalone and phenytoin were found to be 1.60 and 1.83 min respectively. The calibration curve was linear ( $\mathrm{r} 2>$ or $=0.99$ ) ranging from 0.98 to $998 \mathrm{ng} / \mathrm{ml}$ and the lower limit of quantification was $0.98 \mathrm{ng} / \mathrm{mL}$. Interday and Intraday precision were lower than $5 \%(\mathrm{CV})$ and accuracy ranged from 90 to $110 \%$ in terms of percent accuracy. Mean extraction recovery was found to be above $82 \%$. The method was successfully demonstrated for evaluation of pharmacokinetic profile of metaxalone in male Sprague dawley rats and validated for excellent selectivity, accuracy, precision, recovery and stability.
\end{abstract}

Keywords: Electrospray Ionization; Metaxalone; HPLC; Mass detection; Rat plasma; Validation

Abbreviations: CV: Coefficient Variation; HPLC: High Performance Liquid Chromatography; IS: Internal Standard; LC: Liquid Chromatography; LC-MS/MS: Liquid Chromatography -Mass Spectrometry / Mass Spectrometry LLOQ: Lower Limit of Quantitation; LQC: Low Quality Control; MQC: Medium Quality Control; HQC: High Quality Control; PK: Pharmacokinetics; QC: Quality Control; RP: Reverse Phase; CE: Collision energy; TK: Toxicokinetic studies; ESI: Electrospray Ionization; APCI: Atmospheric Pressure Chemical Ionization; BCS: Biopharmaceutics Classification System; MRM: Multiple Reaction Monitoring; CAD: Collision Activated Deactivation; UV: Ultraviolet spectrophotometry; $\mathrm{C}_{\max }$ : The maximum plasma concentration of the drug; psi: Pounds per square inch

\section{Introduction}

Metaxalone has the molecular formula $\mathrm{C} 12 \mathrm{H} 15 \mathrm{NO} 3$ and chemical name 5-[(3,5-dimethylphenoxy)methyl]-2-oxazolidinone) with a molecular mass of $221.26 \mathrm{~g} / \mathrm{mol}$ and absorption maxima around 280 $\mathrm{nm}$. Metaxalone belong to the BCS class II of centrally acting skeletal muscle relaxant drug with antispasmodic effect [1]. Metaxalone belongs to non benzodiazepine antispasmodics with a structure similar to mephenaxalone nucleus [2]. Metaxalone (skelaxin) got FDA approval in 1962 by King Pharmaceuticals mainly for the treatment of acute, painful and musculoskeletal conditions like fractures, dislocations, and trauma to tendons and ligaments and other measures for the relief of discomforts [3]. The mode of action of the metaxalone is clearly unknown but hypothesized as CNS depressant drug which causes skeletal muscle relaxation and sedation [4]. It acts through inhibiting interneuronal activity and blocking polysynaptic reflex pathways at spinal cord and at descending reticular formation in brain but leaving monosynaptic pathways intact like other similar class of skeletal muscle relaxants $[5,6]$. Metaxalone directly does not cause any relaxant effect on tense skeletal muscles or on the contractile mechanism of striated muscle, the motor end plate or the nerve fiber in humans.
Metaxalone has the advantage of reduced sedation, abusing potential and limited accumulation because of its short biological half life [7]. Orally administered metaxalone shows improved exposure (AUC and $\mathrm{C}_{\max }$ ) after standardized high fat meal. Metaxalone has extensive tissue distribution and gets metabolized in liver and excreted through urine [8]. The drug is not recommended for patients with significant renal, hepatic disease and drug induced anaemias [9].

Literature survey has revealed that there only few methods were reported for the determination of metaxalone in plasma by liquid chromatography. Methods reported in the literature for the estimation of metaxalone in bulk and biological fluids include soft ionization interfaces like electrospray ionization (ESI) for determining metaxalone (LC-MS/MS) [10], ultraviolet spectroscopy with LC Chromatography method (HPLC-UV) [11], gas chromatography with flame ionization detection [12,13], gas chromatography with mass detection $[13,14]$. The quantification of drugs, metabolites and poisonous chemicals from biological fluids using mass spectrometry has gained importance in forensic toxicology, clinical and pharmaceutical sector for wide range of application [15].

From the literature survey, reported methods are mainly designed for human biological samples typically above $0.2 \mathrm{~mL}$ of human plasma

${ }^{*}$ Corresponding author: K.Karthikeyan, Department of Pharmaceutical Quality Assurance, Manipal College of Pharmaceutical Sciences, Manipal University, Madhava Nagar, Manipal - 576104, Karnataka, India, Tel: +91 8760342191 E-mail: kartiprabhu@gmail.com

Received February 03, 2012; Accepted April 25, 2012; Published April 28, 2012

Citation: Kandasamy K, Gowdra VS, Nammalvar H, Govindarajan AKS (2012) Bioanalytical Method Development, Validation and Quantification of Metaxalone in Rat Plasma by Liquid Chromatography Tandem Mass Spectrometry. J Bioanal Biomed S6: 006. doi:10.4172/1948-593X.S6-006

Copyright: (c) 2012 Kandasamy K, et al. This is an open-access article distributed under the terms of the Creative Commons Attribution License, which permits unrestricted use, distribution, and reproduction in any medium, provided the original author and source are credited. 
Citation: Kandasamy K, Gowdra VS, Nammalvar H, Govindarajan AKS (2012) Bioanalytical Method Development, Validation and Quantification of Metaxalone in Rat Plasma by Liquid Chromatography Tandem Mass Spectrometry. J Bioanal Biomed S6: 006. doi:10.4172/1948-593X. S6-006

reveals the usage of high quantity of sample in terms of volume, high solvent consumption and tedious sample processing includes control of the factors like $\mathrm{pH}$, extraction solvent, evaporating temperature which is highly time consuming and laborious analysis. Consequently, in rodents very little plasma volume would be available from each animal for processing. Under the scope of this view, aim of our research work is to develop a highly specific, reliable and sensitive method for metaxalone determination in rat plasma that proves to be of immense importance for conducting preclinical studies efficiently in terms of less sample volume, short run time, less tedious processing and sensitive analysis. Hence, a highly sensitive isocratic LC-MS/MS method was developed and validated according to the international guidelines for quantifying metaxalone in rat plasma at a concentration range $(0.98$ $\mathrm{ng} / \mathrm{mL}$ ). Furthermore, a pharmacokinetics study of metaxalone in rat model was conducted, in order to validate the method in study samples

\section{Materials and Methods}

\section{Chemicals and reagents}

Metaxalone (CAS Registry No, 1665-48-1) (Figure 1) of the highest quality has been purchased from sigma Aldrich (Mumbai, India) and Phenytoin (Internal Standard) (CAS Registry no, 57-410) (Figure 1) was kindly donated by Torrent Pharmaceuticals limited (Ahmedabad, India). HPLC grade Methanol 99.8\% was obtained from Merck chemicals (Bangalore, India). Water was purified through a Milli-Q UV plus system supplied by Millipore Pvt Ltd (Bangalore, India). Ammonium acetate, Acetic acid and Trichloroacetic acid were of analytical reagent grade supplied by Merck Chemicals (Bangalore, India) and SD fine chemicals (Mumbai, India) respectively.

\section{Instrumentation}

LC-MS/MS analysis was performed on Applied Biosystems/MDS SCIEX API 4000 LC-MS/MS triple quadrupole mass spectrometry with ESI source and is enhanced by the high degree of automation and data processing capabilities of Analyst software supplied by Labindia Instrument Pvt. Ltd. (Gurgaon, India). The LC part consists of Shimadzu auto sampler LC-10 series chromatographic system (Shimadzu Corporation, Kyoto, Japan) equipped with dual pump (LC10AT-VP). The column oven employed (CTO-10AS VP) and vacuum suction pump was Varian HS 602 Vacuum Pump supplied by Agilent Technologies India Pvt. Ltd. (Haryana, India)

\section{Chromatographic condition}

Chromatographic separations were achieved by using Agilent XDB $C_{18}$ column $(100 \times 4.6 \mathrm{~mm}, 5 \mu \mathrm{m})$. The mobile phase consisted of methanol and $5 \mathrm{~mm}$ ammonium acetate buffer in the ratio of 80:20 $\mathrm{v} / \mathrm{v}$. The rinsing solution used was made of methanol and water (80:20) with $0.05 \%$ acetic acid. All separations were performed isocratically at a flow rate of $0.6 \mathrm{~mL} / \mathrm{min}$ and the injection volume was $5 \mu \mathrm{l}$. The column oven was kept at $40^{\circ} \mathrm{C}$ throughout the analysis. The effluent was ionized by positive electrospray ionization mode and detected by mass spectrometry.

\section{Mass Spectrometric condition}

Mass spectrometric data were acquired in positive ion mode with the following ESI-MS parameters: curtain gas flow rate 15 psi; collision gas flow rate 10 psi; ion source gas (Gs1 and Gs2) were 40 psi and 45 psi, respectively; ion spray voltage $5500 \mathrm{~V}$; dwell time for each transition $200 \mathrm{~ms}$; inter channel delay was $5 \mathrm{~ms}$ and transfer capillary temperature is $550^{\circ} \mathrm{C}$. The curtain gas and ion source gases were nitrogen. Data

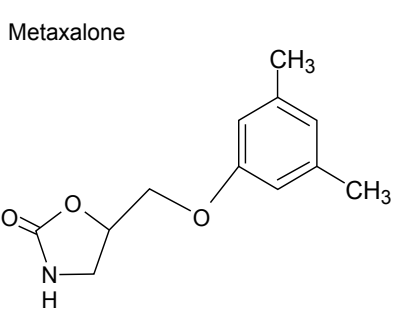

Phenytoin

Figure 1: Chemical structure of Metaxalone and phenytoin.

\begin{tabular}{|c|c|c|}
\hline \multicolumn{3}{|c|}{ Mass Spectrometric Condition } \\
\hline $\begin{array}{c}\text { Name of compound } \\
\begin{array}{c}\text { Molecular weight of free compound } \\
\text { (base / acid) }\end{array}\end{array}$ Analyte: Metaxalone & $\begin{array}{c}\text { Internal standard: } \\
\text { Phenytoin }\end{array}$ \\
\hline MRM transitions (m/z) & 221.252 & 252.268 \\
\hline Declustering potential (eV) & 60 & $253.2 / 182.2$ \\
\hline Entrance potential (eV) & 10 & 75 \\
\hline Collision energy (eV) & 20 & 10 \\
\hline Collision cell exit potential (eV) & 13 & 13 \\
\hline
\end{tabular}

Table 1: Mass Spectrometric condition.

were recorded in MRM mode. MS/MS optimization for metaxalone and phenytoin were performed using $100 \mathrm{ng} / \mathrm{mL}$ concentrations. The precursor ions and LC-MS/MS parameters are displayed in Table 1.

\section{Preparation of stock and standard solutions}

The metaxalone standard was weighed twice separately and prepared separately using methanol and water (1:1) to yield two primary standard stock solutions ( 1 and 2 ) with a concentration of $1 \mathrm{mg} / \mathrm{mL}$. Secondary and working stock solutions for the calibration curve were prepared from metaxalone primary stock solution-1 by methanol and water (1:1). The quality controls working stock solution were prepared from primary stock solution- 2 by methanol and water (1:1). These working stock solutions (1 and 2) were further diluted to obtain metaxalone calibration spiking stock solution for the final concentrations of $0.98,1.95,3.90,7.80,15.61,31.18,62.37,124.75$, $249.50,499.00,998.00 \mathrm{ng} / \mathrm{mL}$ and concentrations of $(2.94,399.2$, and $798.4 \mathrm{ng} / \mathrm{mL}$ ) quality control spiking stock solutions were prepared. The internal standard (Phenytoin) was weighed and prepared separately using methanol and water (1:1) to obtain a primary stock solution of 1 $\mathrm{mg} / \mathrm{mL}$. The working internal standard solution with a concentration of $200 \mathrm{ng} / \mathrm{mL}$ was prepared by diluting the primary stock solution with methanol.

\section{Extraction of metaxalone from rat plasma}

Extraction of metaxalone from rat plasma sample was carried out by using simple protein precipitation method. The protein precipitation was carried using methanol with $0.1 \%$ trichloroacetic acid as precipitating agent. The calibration curve sample preparation involves using $47.5 \mu \mathrm{l}$ of rat plasma and $2.5 \mu \mathrm{l}$ of calibration curve spiking solutions. From this mixture take $25 \mu \mathrm{l}$ add $350 \mu \mathrm{l}$ of methanol containing $0.1 \%$ trichloroacetic acid and $25 \mu \mathrm{l}$ of internal standard in methanol. For the samples $25 \mu \mathrm{l}$ of vortexed plasma was taken and 
Citation: Kandasamy K, Gowdra VS, Nammalvar H, Govindarajan AKS (2012) Bioanalytical Method Development, Validation and Quantification of Metaxalone in Rat Plasma by Liquid Chromatography Tandem Mass Spectrometry. J Bioanal Biomed S6: 006. doi:10.4172/1948-593X. S6-006

Page 3 of 7

$350 \mu \mathrm{l}$ of methanol containing $0.1 \%$ trichloroacetic acid and $25 \mu \mathrm{l}$ of internal standard in methanol was added.

The Calibration curve samples and sample mixtures were vortexed for $5 \mathrm{~min}$ at $885 \mathrm{~g}$ and centrifuged at $19283 \mathrm{~g}$ for $10 \mathrm{~min}$. Then 300 $\mu \mathrm{l}$ of supernatant was collected and transferred into the glass vials containing plastic inserts and subjected to LC-MS/MS analysis. The representative chromatograms were shown in Figure 2.

\section{Bioanalytical method validation}

Preparation of calibration curve: The linearity of the method was evaluated by a calibration curve in the range of $0.98-998 \mathrm{ng} /$ $\mathrm{mL}$ of metaxalone, including lower limit of Quantitation (LLOQ). The calibration curve was achieved by plotting the peak area ratios of metaxalone and internal standard versus the concentration of metaxalone by least-squares linear regression analysis. The calibration curve requires a correlation coefficient $\left(r^{2}\right)$ of $>0.99$. The acceptance criteria for each back-calculated standard concentration should be within $15 \%$ of the nominal concentration, except it should not exceed $20 \%$ for the LLOQ. Each validation run consisted of a double blank, system suitability sample, a zero standard, calibration curve consisting of ten non-zero samples covering the total range $(0.98-998 \mathrm{ng} / \mathrm{mL})$ and QC samples at three concentrations ( $n=6$, at each concentration). Such validation runs were generated on six consecutive days.

Accuracy and precision: Intra-day and Inter-day accuracy and precision were determined by duplicate analysis of six sets of samples spiked with four different concentrations of metaxalone at low, medium, high quality control samples $(0.98,399.1,798.4 \mathrm{ng} / \mathrm{mL})$ including LLOQ $(0.98 \mathrm{ng} / \mathrm{mL})$ within a day or on 6 consecutive days. For acceptance criteria for intra and inter-day precision, accuracy should be within $85-115 \%$ of the nominal concentration and coefficient of variation (\%CV) values should be $<15 \%$ over the calibration range, except at the LLOQ, where accuracy should be between $80-120 \%$ and $\% \mathrm{CV}$ should not be more than $20 \%$

Selectivity: The selectivity of the assay methodology was established using a minimum of six independent sources of the same matrix. There were no interferences from the endogenous material at the retention time for both metaxalone and internal standard (Phenytoin). The representative chromatogram is shown in Figure 3.

Recovery: Recovery of metaxalone was evaluated by comparing the mean peak areas of three extracted low, medium and high quality control samples to mean peak areas of three neat reference solutions (un-extracted). Recovery of internal standard was evaluated at a concentration of $200 \mathrm{ng} / \mathrm{mL}$ and corresponding mean peak area of the extracted samples compared to the mean peak areas of neat reference solutions. Recovery of the analyte need not be $100 \%$, but the extent of recovery for analyte (metaxalone) and internal standard (Phenytoin) should be consistent and reproducible.

Stability: In order to find out the stability of metaxalone in rat plasma, bench top stability, freeze thaw stability, auto injector stability and long term stability studies were carried out by using six replicates of the low and high plasma quality control samples. For the bench top stability, frozen plasma samples were kept at room temperature for $24 \mathrm{hr}$ before sample preparation. Freeze-thaw stability of the samples was obtained over three freeze-thaw cycles, by thawing at room temperature for 2-3 hr and refrozen for 12-24 hr for each cycle. Auto sampler stability of metaxalone was tested by processed and reconstituted low and high plasma QC samples, which were injected $24 \mathrm{hr}$ after reconstitution and were compared with freshly prepared QC samples. Long term stability of metaxalone in rat plasma was tested after storage at approximately $-70^{\circ} \mathrm{C}$ for 30 days. For the acceptance criteria of stability, the deviation compared to the freshly prepared standard should be within $\pm 15 \%$ of the nominal concentration.

Matrix effect: The matrix effect was performed in 6 different lots of rat plasma by taking $47.5 \mu \mathrm{l}$ of rat plasma and $2.5 \mu \mathrm{l}$ of methanol: water (1:1) solution. From the mixture, take $25 \mu \mathrm{l}$ and add $375 \mu \mathrm{l}$ of blank methanol containing $0.1 \%$ trichloroacetic acid. This blank mixture was vortexed for $5 \mathrm{~min}$ at $885 \mathrm{~g}$ and centrifuged at $19283 \mathrm{~g}$ for $8 \mathrm{~min}$ to prepare the extracted blank. The aqueous equivalent solution was prepared by taking $25 \mu \mathrm{l}$ of water and adding $25 \mu \mathrm{l}$ of internal standard along with $350 \mu \mathrm{l}$ of methanol containing $0.1 \%$ trichloroacetic acid. The extracted blank supernatant and aqueous equivalent solution were mixed in a ratio of (1:1) solution. The blank aqueous solution was prepared by mixing $25 \mu \mathrm{l}$ of water along with $375 \mu \mathrm{l}$ of methanol and subjected to vortexing. The neat solution and post extracted solution

XIC of +MRM (3 pairs): 222.2/161.0 amu from Sample

Max.
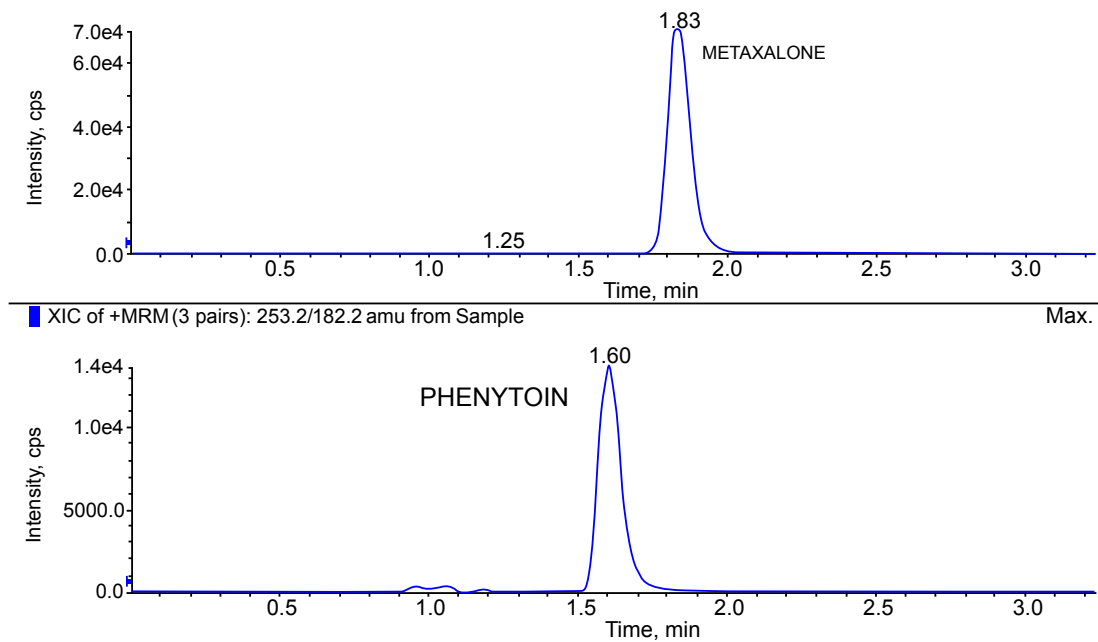

Figure 2: Representative chromatogram of metaxalone in rat plasma. 
Citation: Kandasamy K, Gowdra VS, Nammalvar H, Govindarajan AKS (2012) Bioanalytical Method Development, Validation and Quantification of Metaxalone in Rat Plasma by Liquid Chromatography Tandem Mass Spectrometry. J Bioanal Biomed S6: 006. doi:10.4172/1948-593X. S6-006

XIC of +MRM (3 pairs): 222.2/161.0 amu from Sample Max
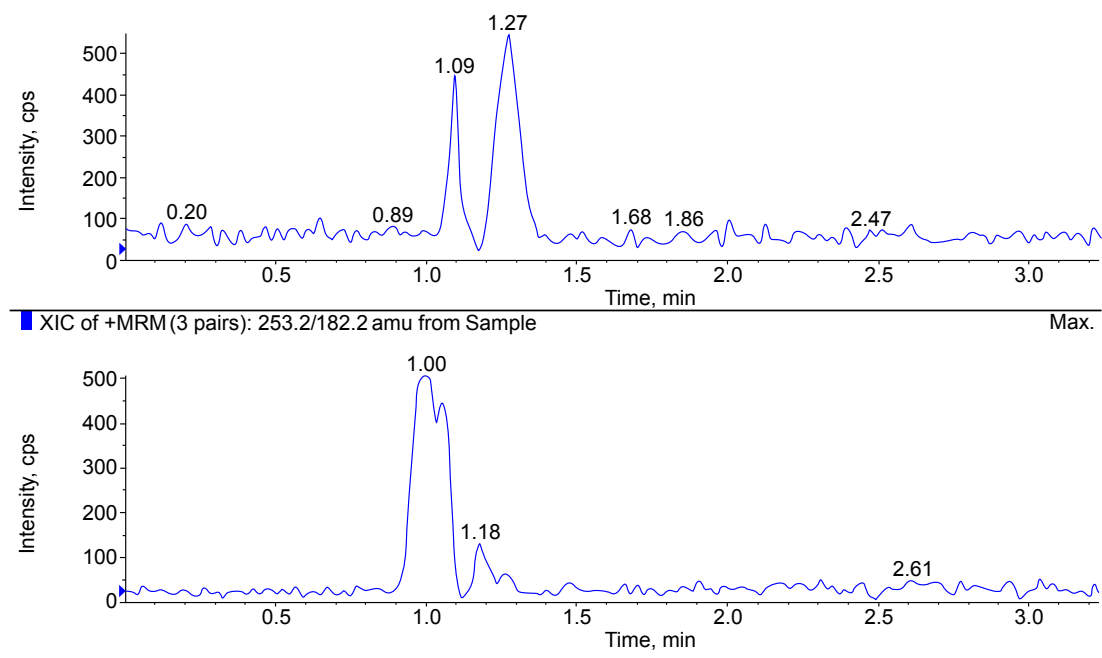

Figure 3: Representative chromatogram of metaxalone in rat plasma.

were prepared by mixing aqueous equivalent solution to both extracted blank and blank aqueous solution in a ratio of (1:1) solution. Both solutions were vortexed and subjected to LC-MS/MS for analysis.

Matrix suppression or enhancement was calculated as follows: $100 \times$ mean peak area of post extracted sample/mean peak area of neat standard solution.

The acceptance criteria for matrix effect implied that the \%CV should be less than $15 \%$ of matrices tested and at least $80 \%$ of matrices should meet the above criteria. The results obtained were displayed in Table 2 .

\section{Results}

\section{Selectivity and optimization of chromatographic conditions}

Plasma matrices were obtained from six different sources and assayed to evaluate the selectivity of the method and the detection of interference. Metaxalone and Phenytoin (internal standard) were well separated from the co-extracted material under the described chromatographic conditions at retention times of 1.60 and $1.83 \mathrm{~min}$ respectively. No endogenous peak from plasma was found to interfere with the elution of either the drug or the internal standard. The LLOQ which could be measured with acceptable accuracy and precision for the analyte $0.98 \mathrm{ng} / \mathrm{mL}$ was established (Figure 4). It indicates that the proposed method is highly selective and specific. Moreover this method does not require any gradient mobile phase system with high sample clean up and less time consumption and can also be automated

\section{Calibration curve}

Linear detector response for the peak-area ratios of the metaxalone to internal standard was observed in the concentration range between 0.98 - $998 \mathrm{ng} / \mathrm{mL}$ with a mean correlation coefficient of 0.9998 . The reason for choosing a wide calibration range for metaxalone PK study is to analyze samples of higher and lower dose concentration and different route of administration like intravenous administration and per oral where the Cmax concentration will be higher for intravenous. The best fit for the calibration curve could be achieved with the linear

\begin{tabular}{|c|c|c|c|}
\hline Day & $r$ & Slope & Intercept \\
\hline 1 & 0.9998 & 0.0001545 & -0.06045 \\
\hline 2 & 0.9997 & 0.0001526 & -0.06333 \\
\hline 3 & 0.9996 & 0.0001535 & -0.06681 \\
\hline 4 & 0.9998 & 0.0001549 & -0.06632 \\
\hline 5 & 0.9997 & 0.0001562 & -0.0619 \\
\hline 6 & 0.9996 & 0.0001552 & -0.06101 \\
\hline Mean & 0.9997 & 0.0001544 & -0.06330 \\
\hline SD & $8.944 \mathrm{E}-05$ & $1.277 \mathrm{E}-06$ & 0.0027 \\
\hline SE & $3.652 \mathrm{E}-05$ & $5.213 \mathrm{E}-07$ & 0.0011 \\
\hline
\end{tabular}

Table 2: Calibration table.

equation $y=m x+c$. The mean linear regression equation of calibration curve for the analyte was $y=0.0001545 \mathrm{x}-0.06045$, where $y$ was the peak area ratio of the analyte to the IS and $x$ was the concentration of the analyte. The results were given in the Table 3 .

\section{Accuracy and precision}

The intra-day accuracy and precision ranged between 95.3$105.11 \%$, and $1.40-1.89 \%$, respectively. The inter-day accuracy and precision ranged from 94.85 to $109.26 \%$ and 1.41 to $1.98 \%$, respectively. The accuracy and precision for intra and interday at the LLOQ and at LQC, MQC, HQC control samples of metaxalone in plasma were within acceptable limits $(n=6)$. The results of the method validation studies presented in Table 4 and 5.

\section{Recovery}

The recovery of metaxalone in plasma was calculated at three QC levels. The response (extracted) compared to that of unextracted samples of the reference solution. The percentage recovery of metaxalone and phenytoin (internal standard) were found to be above $80 \%$. Results are displayed in the Table 6. 
Citation: Kandasamy K, Gowdra VS, Nammalvar H, Govindarajan AKS (2012) Bioanalytical Method Development, Validation and Quantification of Metaxalone in Rat Plasma by Liquid Chromatography Tandem Mass Spectrometry. J Bioanal Biomed S6: 006. doi:10.4172/1948-593X. S6-006

XIC of +MRM (3 pairs): 222.2/161.0 amu from Sample Max. $540.0 \mathrm{cps}$
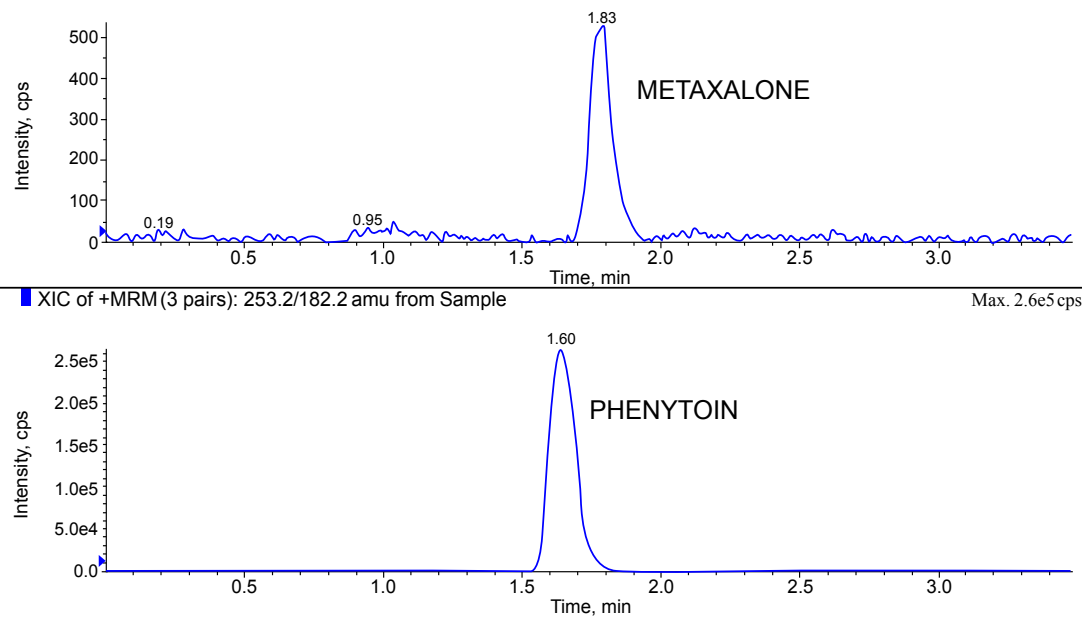

Figure 4: Representative chromatogram of spiked rat plasma at lower limit of quantitation of concentration $0.98 \mathrm{ng} / \mathrm{mL}$.

\section{Stability}

Stock solutions of metaxalone $(1 \mathrm{mg} / \mathrm{mL})$ and internal standard $(1 \mathrm{mg} / \mathrm{mL})$ were separately prepared. The solutions were stable for at least 1 month when stored under light-protected conditions at $4^{\circ} \mathrm{C}$. The stability experiments were aimed at testing all possible conditions that the samples might experience after collecting and prior the analysis. All stability results were summarized in Table 7 . The results of three freezethaw cycles and bench top stability testing $(24 \mathrm{~h})$ when the spiked samples were kept at room temperature indicated that metaxalone was stable in rat plasma under these conditions. Analyte spiked QC samples were stable for at least 30 days if stored in the freezer at $-85^{\circ} \mathrm{C}$. Testing of auto sampler stability of quality control samples indicated that metaxalone would be stable when kept in the auto sampler up to $24 \mathrm{~h}$.

\section{Application of the method}

The assay is sensitive enough to measure the plasma concentration time profile after oral administration of $10 \mathrm{mg} / \mathrm{kg}$ dose of metaxalone in a group of 3 male SD rats weighing about 200-250 g under fasted

\begin{tabular}{|c|c|c|c|}
\hline $\begin{array}{c}\text { Concentration } \\
\text { added }(\mathrm{ng} / \mathrm{ml})\end{array}$ & $\begin{array}{c}\text { Concentration found } \\
(\text { mean } \pm \text { SD) }(\mathrm{ng} / \mathrm{ml})\end{array}$ & \%CV & $\%$ Bias \\
\hline 0.98 & $0.96 \pm 0.019$ & 1.72 & -1.49 \\
\hline 2.94 & $2.91 \pm 0.033$ & 1.45 & -1.25 \\
\hline 400 & $398.11 \pm 1.390$ & 1.40 & -2.45 \\
\hline 800 & $787.26 \pm 1.993$ & 1.89 & -3.67 \\
\hline \multicolumn{3}{|c|}{ Table 3: Intraday precision and accuracy $(\mathrm{n}=6)}$. \\
\hline
\end{tabular}

\begin{tabular}{|c|c|c|c|}
\hline $\begin{array}{c}\text { Concentration } \\
\text { added }(\mathrm{ng} / \mathrm{ml})\end{array}$ & $\begin{array}{c}\text { Concentration found } \\
(\text { mean } \pm \text { SD) }(\mathrm{ng} / \mathrm{ml})\end{array}$ & \%CV & \%Bias \\
\hline 0.98 & $0.97 \pm 0.034$ & 1.98 & -1.40 \\
\hline 2.94 & $2.85 \pm 0.133$ & 1.99 & -2.31 \\
\hline 400 & $390 \pm 0.520$ & 1.41 & -1.90 \\
\hline 800 & $802.24 \pm 1.675$ & 1.67 & -3.05 \\
\hline \multicolumn{3}{|c|}{ Table 4: Interday Accuracy and precision $(\mathrm{n}=6)}$. \\
\hline
\end{tabular}

\begin{tabular}{|c|c|c|c|}
\hline Metaxalone & $\begin{array}{c}\text { LQC } \\
\%\end{array}$ & $\begin{array}{c}\text { MQC } \\
\%\end{array}$ & $\begin{array}{c}\text { HQC } \\
\%\end{array}$ \\
\hline Extraction recovery of six different & 81.22 & 83.15 & 82.11 \\
aliquots of rat plasma & 83.05 & 82.21 & 83.97 \\
& 82.23 & 84.11 & 82.14 \\
& 84.13 & 83.17 & 84.12 \\
& 82.02 & 82.21 & 83.13 \\
Mean of extraction recovery & 81.55 & 83.16 & 84.21 \\
& & & \\
\hline Phenytoin (IS) & 82.36 & 83.00 & 83.28 \\
\hline
\end{tabular}

Table 5: Extraction Recovery $(n=6)$

\begin{tabular}{|c|c|c|c|c|}
\hline \multirow[b]{2}{*}{ Metaxalone } & \multicolumn{2}{|c|}{ LQC(ng/ml) } & \multicolumn{2}{|c|}{$\mathrm{HQC}(\mathrm{ng} / \mathrm{ml})$} \\
\hline & Aqueous & $\begin{array}{c}\text { Post } \\
\text { Extracted }\end{array}$ & Aqueous & $\begin{array}{c}\text { Post } \\
\text { Extracted }\end{array}$ \\
\hline \multirow{6}{*}{ Peak areas } & 6469 & 5679 & 1842799 & 1711811 \\
\hline & 6404 & 5693 & 1821364 & 1716685 \\
\hline & 6264 & 5675 & 1839656 & 1722664 \\
\hline & 6108 & 5584 & 1813150 & 1725528 \\
\hline & 6328 & 5866 & 1842968 & 1721779 \\
\hline & 6311 & 5722 & 1838605 & 1705920 \\
\hline Mean peak area & 6314.6 & 5699.4 & 1831987 & 1719693.4 \\
\hline $\begin{array}{l}\text { Relative standard } \\
\text { deviation }\end{array}$ & 1.968627 & 1.618601 & 0.690661 & 0.43241655 \\
\hline Absolute matrix effect & \multicolumn{2}{|c|}{90.257} & \multicolumn{2}{|c|}{93.870} \\
\hline
\end{tabular}

condition. The blood is collected by jugular vein cannulation at the following time intervals $0.08,0.25,0.5,1,2,4,6,8,12,24 \mathrm{hrs}$ and the collected blood was centrifuged at $6287 \mathrm{~g}$ for $5 \mathrm{~min}$ to aliquot out the plasma. The resultant plasma had been successfully employed for the quantitative estimation of metaxalone in samples. The concentration time profile curve for metaxalone is shown in Figure 5.

\section{Discussion}

\section{LCMS/MS optimization}

The LC-MS/MS method for the detection of metaxalone in rat 
Citation: Kandasamy K, Gowdra VS, Nammalvar H, Govindarajan AKS (2012) Bioanalytical Method Development, Validation and Quantification of Metaxalone in Rat Plasma by Liquid Chromatography Tandem Mass Spectrometry. J Bioanal Biomed S6: 006. doi:10.4172/1948-593X. S6-006

Page 6 of 7

plasma was investigated. Metaxalone was dissolved in methanol: water $(1: 1)$ to obtain the primary stock solution followed by subsequent dilution in methanol (for tuning) and was directly introduced into the mass spectrometer. By optimizing ESI source (ionization) and mass parameters such as collision energy, entrance potential, declustering potential, collision cell exit potential and CAD gas (N2) the protonated molecular ions of metaxalone were obtained. The most suitable collision energy was determined by observing the maximum response obtained for the fragment ion peak $\mathrm{m} / \mathrm{z}$. The product ion mass spectra of the analyte and internal standard are presented in Table 1 where the $[\mathrm{M}+\mathrm{H}]^{+}$ion of the analyte and internal standard were selected as precursor ions. The most abundant fragment ions at $\mathrm{m} / \mathrm{z} 222.2 / 161.0$, and 253.2/182.2 were chosen in the MRM acquisition for metaxalone and the internal standard, respectively.

During the early stages of method development, attempts were made to optimize ESI as an ionization method for metaxalone analysis. In the ESI full scan Q1 spectra of metaxalone, the most intensive $[\mathrm{M}+\mathrm{H}]^{+}$ion was observed along with the less abundant $[\mathrm{M}+\mathrm{H}+\mathrm{CH} 3 \mathrm{OH}]^{+}$ion and other ions. When the source (CAD) energy and collision energy (CE) was set, the abundance of $[\mathrm{M}+\mathrm{H}]^{+}$ion increased whereas other mass ions like $[2 \mathrm{M}+\mathrm{H}]^{+}$and $[\mathrm{M}+\mathrm{H}+\mathrm{CH} 3 \mathrm{OH}]^{+}$decreased. When standard working stock solutions of the analyte were directly injected into the

\begin{tabular}{|c|c|c|c|c|}
\hline $\begin{array}{c}\text { Sample } \\
\text { concentration } \\
(\mathrm{ng} / \mathrm{ml})\end{array}$ & $\begin{array}{c}\text { Fresh sample } \\
\text { concentration } \\
(\mathrm{ng} / \mathrm{ml})\end{array}$ & $\begin{array}{c}\text { Sample } \\
\text { concentration after } \\
\text { storage(ng/ml) }\end{array}$ & $\% \mathrm{CV}$ & $\%$ Bias \\
\hline Short term (24hr) & 2.97 & 2.88 & 1.73 & -2.30 \\
\hline 2.94 & 795.11 & 780.24 & 1.37 & -2.75 \\
\hline 800 & & & & \\
\hline $\begin{array}{c}\text { Three Freeze thaw } \\
\text { cycles }\end{array}$ & 2.94 & 2.80 & 1.34 & -0.98 \\
\hline 2.94 & 804.86 & 781.20 & 2.31 & -2.25 \\
\hline 800 & & & & \\
\hline $\begin{array}{c}\text { Auto sampler } \\
\text { stability }(24 \text { hr) }\end{array}$ & 2.99 & 2.91 & 1.76 & -1.46 \\
\hline 2.94 & 814.23 & 785.65 & 1.54 & 2.35 \\
\hline 800.00 & & & & \\
\hline $\begin{array}{c}\text { Long term } 30 \text { days } \\
\left(-85^{\circ} \mathrm{C}\right)\end{array}$ & 2.93 & 2.76 & 2.79 & -2.33 \\
\hline 2.94 & 797.25 & 760.21 & 1.31 & -3.70 \\
\hline 800.00 & & & & \\
\hline
\end{tabular}

Table 7: Stability details of Metaxalone in rat plasma sample $(n=6)$.

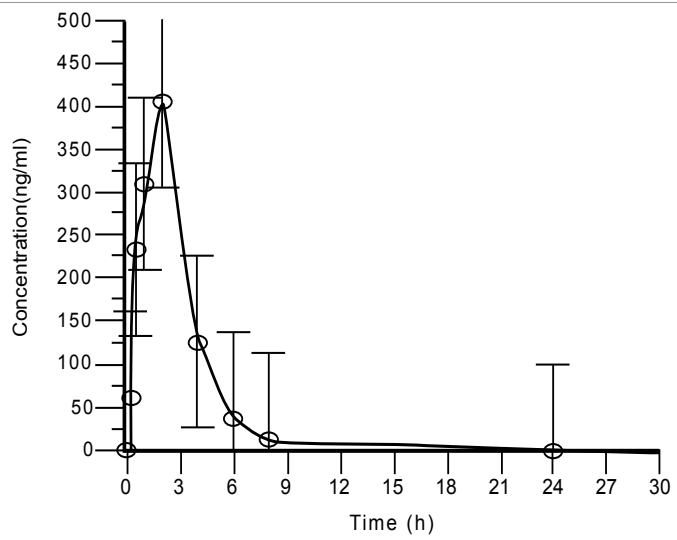

Figure 5: Mean plasma concentration time profile of three healthy SD rats after the administration of single oral dose of $5 \mathrm{mg} / \mathrm{kg}$ of metaxalone under fasted condition. mass spectrometer system, it was observed that the response for the analyte was linear over the mentioned calibrated range. The linearity was found to be best fit for the calibration range when the compound was dissolved in methanol: water (1:1) for preparing the working stock solution. The buffer $\mathrm{pH}$ at 3.0 helped in increasing the linear response by influencing the column properties like retention time, peak shape and peak response with relative variation of $15 \%$ for the analyte. It is accepted as a fact that a non linear range would not be adequate to the pharmacokinetic study. But by controlling the variable parameters like solubility, $\mathrm{pH}$, column, temperature, ionization, less injection volume, obtaining a huge linear range with less possible relative error is possible. As per this method, flow rate and injection volume was set at $0.6 \mathrm{~mL} / \mathrm{min}$ and $5 \mu \mathrm{L}$ injection volume. Unlike reported paper [10], split was not employed in this method because of low flow rate. Since the basic concept of increasing the flow rate with high split ratio of 10:90 is to fasten the elution time and simultaneously maintain ionization for high flow rates through mass. Generally split ratio tends to change with changes in back pressure and expensive in terms of high solvent consumption. But, in this method, no split employed and that possibly decreases solvent consumption, improves reproducibility, increase column life and simultaneously declines chemical noise. It is also important to compare the column length, since this method involves shorter column length $(100 \mathrm{~mm} \times 4.6 \mathrm{~mm})$, indicating fast elution with shorter run time. The $\mathrm{C}_{\max }$ found for rat (intra peritoneal dose) was below $900 \mathrm{ng} / \mathrm{mL}$, but the reason for huge linearity range is to make sure that the method is capable for analyzing higher and lower concentration obtained from both Intravenous and per oral dose of metaxalone. Hence, this method is validated for the linearity range from $0.98-998 \mathrm{ng} / \mathrm{mL}$. During an early phase of method development attempts were made to choose the right column, since the columns like Kromasil C8, Phenomenex Luna C8, Waters symmetry C8, showed that the analyte eluted within the void volume with bad peak shape and poor area response, but as we tried to improve retention time through C18 columns, even though the area response and peak shape was improved considerably. The best $\mathrm{C} 18$ column, chosen based on separation, reproducibility, and response. Taking into account the non polarity nature of the metaxalone, liquid liquid extraction had been proven to be an effective technique in the published methods. However, liquid liquid extraction was found to be time consuming, cost expensive, requires personal manipulation. When a huge number of samples have to be analyzed, it is a potential source of errors. Also, most of these methods lacks sensitivity and needs relatively large volumes of sample $(\geq 0.200 \mathrm{~mL})$ and solvents for analysis. Consequently, these methods are found to be unsatisfactory for pharmacokinetic application studies involving small laboratory animals like rodents. Therefore, different trails are taken with protein precipitation method for the sample preparation to make processing simpler and less time consuming for analysis. Different extraction trials was carried out at acidic, neutral and alkaline $\mathrm{pH}$ in different protein precipitating solvents, showed that the metaxalone could be quantitatively extracted from plasma when acidified with $0.1 \%$ trichloroacetic acid in methanol. Employing a combination of methanol and trichloroacetic acid resulted in high recovery of analyte without increase in endogenous peaks. The trichloroacetic acid acts by ion pairing mechanism which acts by ion pairing to the molecule and decreases/increases its hydrophilicity/ hydrophobicity and resulting in enhanced recovery of the analyte.

Since ESI positive ion mode shows good sensitivity, selectivity and specificity, the ESI source was chosen for this wider linear range for the analyte. In addition during sample preparation, by liquid liquid 
Citation: Kandasamy K, Gowdra VS, Nammalvar H, Govindarajan AKS (2012) Bioanalytical Method Development, Validation and Quantification of Metaxalone in Rat Plasma by Liquid Chromatography Tandem Mass Spectrometry. J Bioanal Biomed S6: 006. doi:10.4172/1948-593X. S6-006

extraction, it is required to reconstitute the residues with the mobile phase but in protein precipitation method, the analyte is injected into the LC-MS/MS with the same extracted organic solvent.

Since, the reported bioanalytical methods for the estimation of metaxalone by HPLC-UV, and mass spectrometry demonstrated that the methods were more tedious and time consuming. But, the present method is simple and robust for fast high throughput samples analysis with less analysis cost for analyzing metaxalone in biological samples. The reported bioanalytical methods were mainly designed using a relatively large volume of plasma sample $(200 \mu \mathrm{l})$. However, in case of preclinical pharmacokinetic and toxic kinetic studies on rodents like rats and mice, in which only microlitre quantities of plasma samples are available for single time bioanalysis, but in case of reanalysis or incurred sample reanalysis, these method reported might not be suitable. These reported methods depend on high sample volume because of its low sensitivity and it is inadequate to calculate the lesser concentration with good specificity due to background chemical noise and interference from biological matrix.

In this proposed method, no interfering peaks were observed at the elution times of metaxalone and phenytoin (IS). The method also had sufficient selectivity, specificity, precision and accuracy over the concentration range of $0.98-998 \mathrm{ng} / \mathrm{mL}$. This method had a quantification limit of $0.98 \mathrm{ng} / \mathrm{mL}$, which was adequate enough to quantify the drug in rat plasma after administration of metaxalone. The developed method requires very low sample volume $(25 \mu \mathrm{L})$. Hence a minimum blood sampling is sufficient; thereby making pharmacokinetic blood sampling study of a single rodent is practicable.

\section{Conclusion}

Since merits of LC compare to other techniques are well recognized, a highly sensitive, specific and reproducible isocratic LC method with mass detection method is more valuable. In addition, along with method development, the method is also validated to quantify the concentration range of $0.98-998 \mathrm{ng} / \mathrm{mL}$ of metaxalone in rat plasma samples and requires only $25 \mu \mathrm{L}$ of sample volume. The LC-MS/MS method presented here fulfils the criteria generally required for the bioanalytical assays. This assay has sufficient sensitivity, selectivity and recovery above $80 \%$, which shows that the method is suitable for pharmacokinetic and toxic kinetic studies of metaxalone. The small sample volume requirement supports the possibility to study the full $\mathrm{PK}$ profile in individual small rodents like mice, rats.

\section{References}

1. See S, Giuzburg R (2008) Choosing a skeletal muscle relaxant. Am Fam Physician 78: 365-370.

2. Beebe FA, Barkin RL, Barkin SA (2005) A clinical and pharmacologic review of skeletal muscle relaxants for musculoskeletal conditions. Am J Ther 12: 151 171.

3. Robert AS, Menelaos K, Rahul R, Myint M (2004) Pharmacological options for low back pain. Semin Pain Med 2: 175-185.

4. Elenbass JK (1980) Centrally acting oral skeletal muscle relaxants. Am J Hosp Pharm 37:1313-1323.

5. Karla AM, Barry L, David F (2005) A fatality involving metaxalone. Forensic Science International 149: 249-251.

6. Bruce RB, Turnbull L, Newman J, Pitts J (1966) Metabolism of Metaxalone. J Med Chem 9: 286-288.

7. Otto M, Cepek L, Ratzka P, Doehlinger S, Boekhoff I, et al. (2004) Efficacy of metaxalone on cognitive function in patients with CJD. Neurology 62: 714-718.

8. Poklis JL, Ropero-Miller JD, Garside D, Winecker RE (2004) Metaxalone (Skelaxin) Related Death. J Anal Toxicol 28: 537-540.

9. Gruszecki AC, Kloda S, Simmons GT, Daly TM, Hardy RW, et al. (2003 Polydrug fatality involving metaxalone. J Forensic Sci 48: 432-434.

10. Ramakrishna VSN,Vishwottam NK, Manoj S, Koteshwara M, Wishu S, et al. (2006) Quantification of Metaxalone in Human Plasma by Liquid Chromatography Coupled to Tandem Mass Spectrometry. J Anal Toxicol 30 245-251.

11. Janice C, Reilly EE, Anton A (2004) Comparison of the dissolution of metaxalone tablets (skelaxin) using USP apparatus 2 and 3. AAPS PharmSciTech 5: E6.

12. Jemal M (2000) High-throughput quantitative bioanalysis by LC-MS/MS Biomed Chromatogr 14: 422-429.

13. Nowatzke W, Woolf E (2007) Best practices during bioanalytical method validation for the characterization of assay reagents and the evaluation of analyte stability in assay standards, quality controls, and study samples. AAPS J 9: E117-E122.

14. Bansal S, DeStefano A (2007) Key elements of bioanalytical method validation for small molecules. AAPS J 9: E109-E114.

15. Causon $R$ (1997) Validation of chromatographic methods in biomedical analysis viewpoint and discussion. J Chromatogr B Biomed Sci Appl 689: 175-80. 